\title{
On the Main Problems and Countermeasures of Green Travel in Wuhan
}

\author{
Liang-Bin Cheng ${ }^{*}$ and Mengke $\mathrm{Hu}$ \\ School of Marxism, Huazhong University of Science and Technology, Wuhan 430074, China
}

\begin{abstract}
At present, the main problems of green travel in Wuhan are as follows: serious segmentation, insufficient promotion of green new energy vehicles, single way of QR code scanning, low public participation, etc. In order to solve these problems and further improve the green travel rate and air quality in Wuhan, the following countermeasures need to be adopted: improving the top-level design, strengthening tax relief and financial support, establishing a market-oriented incentive mechanism, developing green public transport, regularly making statistics and releasing relevant data of green travel, strengthening the education and publicity of green travel, etc. Keywords: Green travel, Problems, Countermeasures, Wuhan.
\end{abstract}

\section{Introduction}

In 2013, China suffered from severe fog and haze, with the average number of haze days reaching 29.9 days across the country, spreading to 25 provinces [1]. In that year, Wuhan had recorded low number of days with good air quality, with a rate of only 44.1 percent. This situation has a great impact on people's health, work and life. Obviously, the cause of haze weather is closely related to people's production and life style (especially their travel mode). In recent years, Wuhan has witnessed a rapid growth of motor vehicles. By the end of 2019, the number of motor vehicles in Wuhan has reached 3.3 million, an increase of $14.6 \%$ over 2017. This has led to an increase in pollutants such as carbon monoxide, nitrogen oxides, PM2.5 and PM10. According to calculations, the current contribution rate of motor vehicles in Wuhan to the PM2.5 concentration in the atmospheric environment has reached $27 \%[2]$. Therefore, it has become the common voice and basic appeal of the people to vigorously promote green travel, greatly improve air quality and effectively curb the use of non-green new energy vehicles.

\section{The main problems of green travel in Wuhan and its causes}

\subsection{The fragmentation is serious and the operation mechanism is not smooth}

In May 2019, the Ministry of Transport, the Central Propaganda Department and other 12 departments and units issued the "Green Travel Action Plan (2019-2022)". This means that

* Corresponding author: chengliangbin@hust.edu.cn 
these 12 departments and units are the governance principal parts of green travel work. However, the action plan did not mention anything about how the 12 departments and units will communicate and coordinate their responsibilities.

In Wuhan, green travel mainly refers to travel within the city, which may not involve so many departments and units, but at least involve 9 departments and units, such as Transportation Bureau, Publicity Department, Development and Reform Commission, Environmental Protection Bureau, Public Security Bureau, Urban Management Bureau, Land and Resources Bureau, Public Transport Group, Metro Group, etc. But so far, Wuhan has not set up relevant organizations and coordination agencies, which make it difficult to fully integrate the advantageous resources of these departments and units, and even more or less appears the situation of separate governance [3]. For example, WeChat mini program of "Low-carbon Military Transportation" launched by the National Development and Reform Commission is well-targeted, effective, time-sensitive, and affordable. It does not fall behind other similar programs, however, it is not well known in Wuhan and the number of registered people is small, which obviously has a great relationship with insufficient publicity.

\subsection{Insufficient promotion of green new energy vehicles}

By the end of 2018, the number of new energy vehicles in Shanghai had reached 240,000, and the total number of registered new energy vehicles in Shenzhen had reached 270,000. In April 2019, Tianjin also had 125,000 new energy vehicles. Relatively speaking, the growth of Wuhan's new energy vehicles is relatively slow. As of February 2019, there are only 53790 new energy vehicles in the city [4].

In terms of green new energy buses, Hangzhou took the lead in introducing new environment-friendly buses such as gas-electric hybrid and natural gas as early as 2008 . By the end of 2016, the proportion of green buses in Hangzhou had reached $96.98 \%$, leading the country. In 2017, Shenzhen became the first city in the world to make its buses $100 \%$ electric. The city of Wuhan did not start purchasing pure electric buses until 2014. In 2015, it stopped purchasing diesel buses and started to replace old vehicles with pure electric or natural gas buses. By the end of 2018, the proportion of Wuhan's green new energy buses (including pure electric buses and natural gas) have reached $62 \%$, and it is expected to reach $80 \%$ by 2020 [5]. Compared with Shenzhen, Hangzhou and other cities, there is still a big gap in these data.

In addition, in 2018, gasoline vehicles accounted for $91.67 \%$ of Wuhan's motor vehicles, diesel vehicles accounted for $7.70 \%$, and the two together accounted for $99.5 \%$ [6]. This data reflects that the promotion of green new energy vehicles in Wuhan has just started, and there is still much space for development in the future.

The main reasons for the insufficient promotion of green new energy vehicles in Wuhan are as follows: First, insufficient financial subsidies. At present, when Wuhan enterprises purchase a new energy vehicle, the state subsidy and local government subsidies together account for about $60 \%$ of the car purchase, but the proportion in Xiangyang is about $80 \%$. Second, the supporting facilities are not perfect. Due to urban development and transformation, some bus parking yards have been demolished, making it impossible to centralize charging and parking of new energy buses at night.

\subsection{Public transport code scanning mode is relatively simple}

At present, Shenzhen has realized seven modes of travel payment, including one-way tickets, national transportation all-in-one cards, UnionPay Quick Pass, etc. On the basis of traditional payment methods, Hangzhou has added a variety of payment methods such as subway official APP, Alipay APP scanning code and so on. Beijing also launched the "One Code" in public 
transportation on May 16, 2020. The "One Code" service breaks the barriers between different subway and bus scenes, and realizes the interconnection among various public transportation apps (Beijing Bus APP, Yitongxing APP, Beijing One Card APP), that is, passengers can use any APP code to take the bus or subway, saving you the trouble of downloading different applications.

Relatively speaking, mobile payment in Wuhan is a bit inferior. There are only two kinds of mobile bus payment, one is Alipay scan code bus, the other is Wuhan pass and other physical card payment card; besides, the metro only supports payment with physical cards such as Wuhan Tong and exclusive apps. Although Wuhan Metro launched the mobile phone scan code to purchase tickets and scan code gate functions in December 2017, it only supports mobile phones with NFC function. Passengers also need to download and install the "Metro New Era" APP before they can use it after registration and binding. In other words, the Wuhan Metro does not support UnionPay Quick Pass, Tencent ride code, Alipay scan code and other ways of crossing the gate. In addition, as of June 2019, a total of 245 cities in China have been connected by the all-in-one transport card. At present, buses and ferries in most parts of Wuhan have joined the system and enjoy a 20\% discount, but Wuhan Metro has not yet joined the system.

\subsection{Insufficient publicity of green travel and low public participation}

Since China joined the 922 Green Travel campaign, various activities have been carried out throughout the country to mobilize and enhance the public's awareness of green travel. From September 2013 to September 2019, the "Green travel, smooth Beijing" traffic propaganda team of Beijing Municipal Commission of Transport held more than 1,700 activities for people from all walks of life, and the number of participants reached 300,000. Compared with Beijing, Wuhan's green travel campaigns have some problems in terms of mobilizing the public to participate, such as a small range of audiences and a low level of public participation. At present, there are only more than 300 volunteers in the green travel publicity campaign, and the publicity scope and intensity are limited. As a result, the publicity target group is only a small number of citizens, which has not been widely spread to all groups in the whole society[7]. In particular, it has not played a propagandistic and educational role on the main force of green travel such as salaried employees.

\section{Countermeasures for green travel in Wuhan}

\subsection{To improve top-level design and strengthen system governance}

We can learn from the Hangzhou "Five Waters Co-governance Office" with relevant experience in institutional setting, the Wuhan Green Travel Work Leading Group should be established under the Wuhan Environmental Protection Commission to coordinate and manage the city's green travel related work. It is recommended that the deputy mayor in charge of transportation or the environment concurrently serve as the leader of the green travel work leading group. In terms of constituent units, the Transportation Bureau, the Environmental Protection Bureau, the Urban Management Bureau, the Public Security Bureau, the Development and Reform Commission, the Land and Resources Bureau, the Publicity Department and other departments with green travel development planning function, publicity function or law enforcement power shall be included, and the relevant persons in charge shall be the team members. An organizational structure with centralized functions and unified responsibilities shall be formed, whose functions are to guide, coordinate, supervise, assess and publicize, and carry out comprehensive management for 
those that no one has managed before, dare not manage, do not want to manage or cannot manage, and make overall arrangements for green travel work, which shall be implemented by relevant departments. It is recommended to include a green travel project in the "Wuhan Embracing Blue Sky Action Plan 2020", so that green travel work should be included in the annual specific plan (the plan did not explicitly mention green travel in previous years).

In the "Wuhan Motor Vehicle Exhaust Pollution Prevention Regulations" (approved by the Standing Committee of the Municipal People's Congress on September 17, 2014, and formally implemented on March 1, 2015), clear regulations on green travel are given: "organizations, groups, enterprises, institutions and other organizations shall strengthen motor vehicle exhaust pollution control laws, regulations, and civilized traffic, green travel propaganda", "The Municipal People's Government should create conditions to facilitate citizens' green travel." As local regulations, these regulations are relatively advanced nationwide, and their ideas are relatively advanced, reflecting the Wuhan Municipal Party Committee and government still attaches great importance to green travel. However, in order to make these regulations come true, it is necessary for the municipal Party committee and the municipal government to carry out strong system governance.

\subsection{To strengthen tax reduction and financial support}

At present, with the continuous increase in operating costs such as equipment renewal and maintenance, public transportation companies generally suffer from a shortage of funds. Taking the subway as an example, according to the statistics of the "China Urban Rail Transit 2018 Annual Statistics and Analysis Report", the average operating revenue and expenditure ratio of urban rail transit in 2018 was $78 \%$, and only four cities including Hangzhou, Qingdao, Shenzhen, and Beijing had operating income more than $100 \%$, at least not at a loss. The rail transit operations of other 24 cities, including Wuhan, have a certain degree of loss, and they need to rely on financial subsidies to maintain their operations. Therefore, Wuhan can appropriately increase financial support for public transportation in accordance with the development of the public transportation sector under the conditions of local financial strength.

In addition, it is recommended to set up a special fund for green travel development, increase financial subsidies for public infrastructure construction, and realize $100 \%$ new energy for buses[8]; increase funding guarantees for slow-moving system improvements, and encourage and support shared bicycle companies to enter; increase financial support for technology industries such as new energy and information, and encourage relevant companies to develop green and pollution-free vehicle fuels through financial subsidies and tax reductions, so as to produce more energy-efficient and low-carbon environmentally friendly vehicles; increase taxes and fees on the traditional energy-intensive automobile industry, while increasing subsidies for the purchase of new energy vehicles to guide the concept of green and sustainable consumption.

\subsection{To strengthen government-enterprise cooperation and establish market- based incentive mechanisms}

First of all, Wuhan can learn from Japan's “Environmental Protection Points System” (2009), Guangdong's "Carbon Inclusive" (2015), Nanjing's "Riding Points" (2016) and Shenzhen Yantian District's Carbon Coin System (2016). The specific approach is to further improve the "Low Carbon Military Games" platform launched by the Wuhan Development and Reform Commission in June 2019 to improve the platform's positioning, convenience and timeliness. One is to further enhance the positioning of "Low Carbon Military Games", not only for the carbon neutrality of the military games, but also to include the construction of 
an "ecological Wuhan" after the military games; the second is to improve the convenience and timeliness of the platform. For example, the platform's activities such as "organic light food, favorite accompanying cups" and other activities need to be photographed and uploaded, accounting for $40 \%$ of the total activities, and these activities need to be manually audited before they take effect. The review process will not only incur certain manpower and material costs, but also affect the timeliness of points exchange. Regarding the two activities of "low-carbon hotels" and "purchasing green home appliances", we can learn from the experience of Yantian district in Shenzhen. The government confirms green hotels and green home appliances sales brands through inspections and establishes contact with them. If the public goes to the corresponding location to generate transactions, then you can directly scan the $\mathrm{QR}$ code to get points.

Secondly, in view of the key and prominent problems in Wuhan's green travel, corresponding applications will be launched in a timely manner, by mobilizing the enthusiasm of the broad masses of people, internalizing the externalities of green travel, and solving problems in a market way. For example, in response to the important impact of private cars on green travel rate, air quality, and traffic congestion, the Shenzhen Traffic Police launched "Green Travel" (entered on WeChat and Alipay platforms in September 2017) to encourage private cars to travel green (that is, no or less use, disabled during peak hours, etc.). As the "second headquarters" of many technology companies such as Alibaba and Tencent, Wuhan can rely on existing platforms such as Alipay, Tmall and WeChat to effectively graft Internet technology and green travel, and build various platforms for green travel in Wuhan based on market-oriented means.

\subsection{To develop green public transport}

The new energy buses are basically pure electric buses, with zero carbon emissions and only $65 \%$ of the driving cost of diesel buses. They are not only economical and environmentally friendly, but also have low odor and noise, and have extremely high cost-effective. Take Shenzhen as an example, in the past, buses and taxis only accounted for $1 \%$ of the total number of motor vehicles, but the pollution generated accounted for more than $30 \%$ of the city's motor vehicles. After continuing to promote new energy vehicles, "take Shenzhen Bus Group as an example, in the past year, pure electric buses saved about 116,000 tons of fuel and reduced carbon dioxide emissions by about 360,000 tons." [9]

It can be seen that although the increase in the ratio of green and new energy public transportation has no effect on the improvement of green travel rate (according to the current calculation method), but it has a great impact on air quality. Therefore, the city of Wuhan should fully realize the importance of developing green buses, and learn from the earlier and faster development of new energy buses in cities such as Shenzhen and Hangzhou, strengthen the application of new energy technology research and development, accelerate the development of diesel buses, and strive to achieve the goal of $100 \%$ of the green and new energy public transport ratio as soon as possible.

\subsection{To make statistics and release relevant data of green travel regularly}

At present, the data system about green travel in Wuhan is incomplete, and it can't be updated in time. For example, the core data of green travel "green travel rate" so far, the author has not found the official data. However, in 2017, the Ministry of Transport clearly stated in the development goals of the "Opinions on Comprehensively and Deeply Promoting the Development of Green Transportation" that "by 2020, the proportion of green travel in the central urban areas of large and medium-sized cities should reach over 70\%". In 2018, the Wuhan Municipal People's Government clearly pointed out in "Wuhan Urban Construction 
Green Development Implementation Plan (2018-2020)" that it will take three years to "increase the urban public transportation, bicycle, walking and other green travel sharing rate by more than $10 \%$." According to analysis, the "green travel ratio", "green travel sharing rate" and "green travel rate" actually mean the same thing here.

If we don't know the green travel rate of Wuhan at that time, how can we make a targeted plan to ensure that the goal of reaching $70 \%$ or more in 2020 is achieved (if it has not been reached yet)? If we don't know the green travel rate in 2018, it is not rigorous or clear to say that the green travel rate will be increased by more than $10 \%$ by 2020 . Because the base is different, the $10 \%$ increase rate or percentage point is different (such as $50 \%$ of $10 \%$ is 5 percentage points, and $10 \%$ of $90 \%$ is 9 percentage points).

Currently, the governments of Beijing, Shanghai, Chongqing, Nanning, and Bao'an District of Shenzhen all regularly release relevant data such as green travel rates (see Fig.1). These methods have successful experiences of Wuhan to go by.

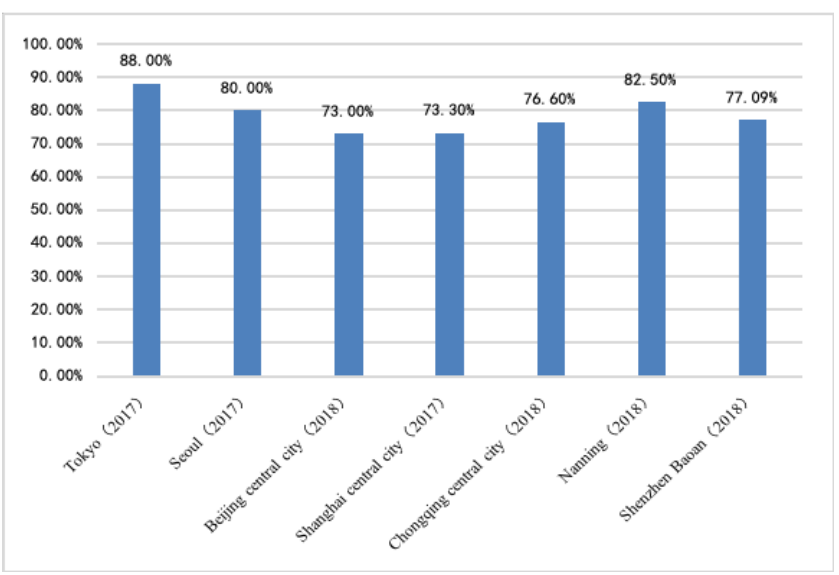

Fig.1. Distribution of green travel rate in some cities (or districts) at home and abroad. (Source: These data are collated from network resources.)

\subsection{To strengthen the education and publicity of green travel}

First of all, we must play the basic role of school education. The Municipal Education Bureau takes the lead in bringing green travel into the education of universities, middle schools and primary schools, so that the newly grown generation will become the pioneers of green travel and active practitioners of the "two mountains" theory. Different education forms and different education plans can be adopted for students of different levels, different ages, and different genders; the first classroom and the second classroom can be organically combined.

Second, we must give play to the leading role of news media. Relying on the green travel promotion month and bus travel Publicity Week held in September every year, Wuhan can put up propaganda posters and broadcast short films in public places such as underground passages and bus station billboards, and carry out activities such as selecting green travel pioneers and collecting typical cases by using traditional media and network channels. At the same time, it is suggested to regularly broadcast the public service advertisement of green travel in the mainstream media, and timely launch the application of promoting green travel, so as to normalize and concretize the publicity work of green travel.

Finally, we must play the key role of communities and non-governmental charity organizations. It is recommended that each community be equipped with volunteers of green travel promoters, and dedicated persons will spread the concept of green travel to different groups in the society through the distribution of brochures and other forms; learn from the 
successful experience of the "green travel, smooth Beijing" traffic propaganda group, and cooperate with "Wuhan green river city" non-governmental environmental protection organizations to form the Wuhan green travel propaganda group, which is composed of experienced volunteers and traffic workers who are struggling in the front line. We can popularize green travel knowledge, improve environmental awareness and form a unique ecological culture brand through vivid real cases and a wide variety of teaching forms [10].

\section{References}

1. Information on http://jl.cnr.cn/ltrt/201312/t20131230_514527688.shtml.

2. R. J. Chen, H. Y. Xie, Y. C. Lin. Journal of China University of Geosciences (Social Sciences Edition), 18(04):95-110 (2018)

3. J. Xia, S. D. Qin, Hubei Agricultural Mechanization, (06),39-43(2013)

4. Information on http://m.evpartner.com/news/detail-46624.html

5. Information on https://www.sohu.com/a/290201525_760385.

6. Wuhan Ecological Environment Bureau. 2018 Wuhan Motor Vehicle Pollution Prevention and Control Annual Report [R] (internal data). Wuhan Ecological Environment Bureau. 2019: 4.

7. Y. Li, Social Sciences Front, (06),265-268(2017)

8. T. Q. Chen, Enterprise Reform and Management, (08),220-222(2019)

9. Information on https://www.sohu.com/a/290201525_760385.

10. R. R. Yang, R. Y. Long, Journal of Wuhan University (Philosophy and Social Sciences Edition), 67(05),13-19(2014) 